
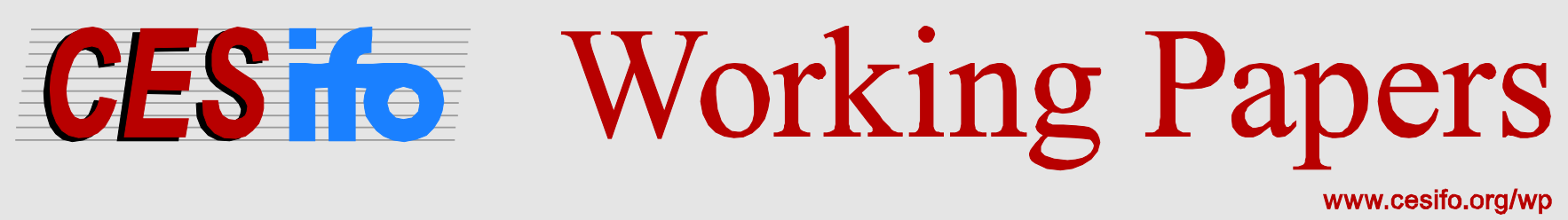

\title{
Regulatory Chill and the Effect of Investor State Dispute Settlements
}

\author{
Eckhard Janeba
}

CESIFO WORKING PAPER NO. 6188

CATEgory 8: Trade Policy

ORIGINAL VERSION: NOVEMBER 2016

THIS VERSION: JULY 2019

An electronic version of the paper may be downloaded

- from the SSRN website:

- from the RePEc website:

- from the CESifo website:

WWw.SSRN.com

www.RePEc.org

www.CESifo-group.org/wp 


\title{
Regulatory Chill and the Effect of Investor State Dispute Settlements
}

\begin{abstract}
Legal conflicts between multinational firms and host governments are often decided by international arbitration panels - as opposed to courts in the host country - due to provisions in international investment agreements known as Investor State Dispute Settlements (ISDS). Critics fear that investor protection such as ISDS make governments reluctant to adopt appropriate policies (regulatory chill). In this paper I develop a theoretical model in which the outcome of cases brought to court is uncertain due to the vagueness of the law protecting investors and a court's inability to correctly identify a state of nature with certainty. I show that from a world welfare perspective there is no underregulation, only an overregulation problem. However, from a national welfare perspective “frivolous” lawsuits may lead to regulatory chill. I also identify conditions under which ISDS can lead to a Pareto improvement which involves simultaneous changes in compensation payments and protection rights relative to a national court.
\end{abstract}

JEL-Codes: F230, F530, H250.

Keywords: Investor State Dispute Settlement, regulatory chill, international investment agreement, foreign direct investment.

\author{
Eckhard Janeba \\ University of Mannheim \\ Department of Economics, L7 3-5 \\ Germany-68131 Mannheim \\ janeba@uni-mannheim.de
}

April 15, 2019

Data Availability Statement: Data sharing is not applicable to this article as no new data were created or analyzed in this study.

In part this paper was completed during a stay at Universite Paris 1. I am very grateful to Stephane Gauthier and Francis Bloch for their hospitality. Many thanks for helpful comments to Harald Fadinger and Andreas Engert, as well as audiences at the CESifo Global Economy conference, and seminars at University of Mannheim, Simon Fraser University, and MPI Munich. I gratefully acknowledge support from the Collaborative Research Center (SFB) 884 "Political Economy of Reforms", funded by the German Research Foundation (DFG). 


\section{Introduction}

"Except in rare circumstances, non-discriminatory regulatory actions by a Party that are designed to protect legitimate public welfare objectives, such as public health, safety and the environment, do not constitute indirect expropriations." Bilateral Investment Treaty Columbia/USA

Legal conflicts between multinational firms and host governments about policy changes are widespread. Often, these conflicts are decided through international arbitration by a panel of expert lawyers, known as Investor State Dispute Settlement (ISDS), instead of courts in the host country. International arbitration is agreed upon in international investment agreements, of which by the end of 2014 there were 3268 in place. In recent years between 50 and 80 ISDS cases have been decided annually, some of which involve substantial amounts of money (UNCTAD, 2015, 2018). ${ }^{1}$

Many conflicts center around the issue of indirect expropriation, which refers to government actions that have a substantial adverse impact on a firm without nationalizing a firm outright. It is difficult to define precisely what indirect expropriation means in practice, in particular since the law shall not prevent a government from rightful regulation. The conceptual vagueness is shown exemplary in the bilateral investment treaty between Columbia and the US, as cited above (see, Nikiema (2012) for a detailed description and legal analysis of similar clauses in other treaties). Courts therefore have some leeway in deciding cases brought to them by firms.

Critics of ISDS from the scientific community (e.g., Gerstetter and Meyer-Ohlendorf, 2013; Tienhaara, 2011) or international advocate groups such as attac fear that international arbitration panels are biased towards multinational firms and more generally may prevent governments from carrying out legitimate policy changes if lawsuits by firms are anticipated, a situation known as regulatory chill. This argument appears to be not fully convincing because regulation with a compensation payment should be worthwhile for the government if the negative effects of missing regulation are sufficiently large. This viewpoint assumes however that only legitimate lawsuits are filed, which may not always be the case, as argued below.

This paper provides a formal framework for the analysis of i) regulatory chill in the presence of foreign direct investment (FDI), and ii) the welfare effects of shifting decision

\footnotetext{
${ }^{1}$ An example is the Swedish energy company Vattenfall that has filed lawsuits in Germany and under ISDS (ICSID) against the German government's revocation of nuclear power plant licenses after the nuclear power incident in Fukushima, asking for compensation in the amount of 3.7 billion Euros; see The Economist, The arbitration game, October 11, 2014
} 
power of conflicts between foreign investors and host countries from a national court to an international body via ISDS. While recent research has looked into the effects of ISDS, discussed in detail below, to the best of my knowledge there is no formal work on regulatory chill and the explicit modeling of court challenges in the context of FDI. Thereby the paper sheds light on the debate of ISDS-based arbitration in recent trade agreements such as CETA and TTP.

The theoretical model has several features that make for a realistic setup. The underlying economic framework is standard: firms are afraid of harmful regulation after entry into the host country, which involves sunk cost. On the other hand, absence of regulation causes a loss (externality) to the host government (such as environmental hazard from production). In the absence of a compensation payment to the firm for harmful regulation the hold up problem induces the well known underinvestment problem. The presence of courts, to which firms may appeal for compensation in case of harmful regulation without compensation, changes the outcome in a nontrivial way. Whether the firm is entitled to compensation by law depends on circumstances, modeled as an uncertain state of nature ex ante. This aspect captures the vagueness of investor protection clauses in investment treaties. Unlike the firm and host government, courts do not perfectly observe the state of nature however, and therefore may make a wrong decision: ruling in favor of compensation even though there should none be paid - thus setting the stage for a frivolous lawsuit-, or not rewarding compensation even though the firm should get it. Moreover, the quality of the court, measured by the probability with which the court correctly identifies the state of nature, is a parameter of the model that allows me to capture potential differences between national courts and international tribunals. Similarly, I vary the strength of the law protecting the firm against regulation without compensation, measured by the ex ante probability of the state of nature that favors the firm.

Within this framework I establish the following insights. First (Prop. 2), the firm files a lawsuit if the state of nature favors the firm to receive compensation for regulation but wasn't offered any under the conditions that i) the court cost are not too high relative to the potential compensation payment and ii) the court quality is of at least intermediate level (the terms low, intermediate and high are well defined in the model). In these cases an imperfect court does not deter the firm from claiming its rights. However, when the firm is not entitled to compensation the firm challenges the host government if the court is of low or intermediate quality and court cost are small because the court may then wrongfully award compensation. This is the case of a frivolous lawsuit, which implies that laws for compensation enforced by courts are not always a remedy against 
the underinvestment problem.

The second result (Prop. 3) shows under which circumstances the host government pays compensation for regulation if it anticipates correctly the legal behavior of the firm (as just described). When the court quality is high, the host government chooses regulation and pays compensation voluntarily when the production externality is high and the firm is entitled to compensation, while not paying compensation when the firm is not entitled to it. This result backs the logic of the proponents of investor protection laws. "Good" regulation is not prevented, and compensation payments are in the self interest of the host government if the stakes are high enough. However, when the court quality is intermediate, the host government never pays compensation regardless of the state of nature and the cost of litigation. Rather the host country either does not to regulate or regulates without compensation. The latter can happen even when the litigation cost are low and the firm is entitled to compensation, as the host government takes a gamble in court if the court may come out wrongly. This result can be seen as an analogue to the frivolous lawsuit by the firm, and could be termed frivolous regulation.

The third finding (Prop. 4 and 5) speaks to the issue of regulatory efficiency and regulatory chill in particular. From a world welfare perspective (combining firm profits and host country welfare) there is no problem of underregulation ex post (after firm entry), only of overregulation. That is, the government regulates the firm even if it should not do it from a world welfare perspective. Therefore, fears of regulatory chill are not justified from a global perspective. At the same time, however, underregulation may occur from a host country perspective in a situation where the firm is not entitled to compensation, but nevertheless would file a lawsuit if facing regulation without compensation. This happens only when court quality is intermediate and court cost are low. Anticipating the lawsuit, the government chooses not to regulate in the first place, thus being deterred by a frivolous lawsuit. This establishes the case of regulatory chill from a host country perspective.

The fourth result (Prop. 6) shows that from an ex ante viewpoint (prior to the state of nature being revealed), firm entry is inefficiently low whenever the host country benefits from inward FDI outweigh the externality associated with it. A remedy for this problem could be to let the government pay an upfront subsidy to the firm. Alternatively, making the likelihood that the firm is entitled to compensation in case of regulation higher achieves the same thing, that is, strengthening investor protection in the law.

The fifth and final result (Prop. $7+8$ ) compares national courts with international tribunals. The two may differ in the level of quality (i.e., the probability of correctly 
identifying the state of nature), the strength of the law in terms of requiring compensation in case of regulation (i.e., the probability of firm entitlement to compensation), and the magnitude of compensation in case of regulation. I show several results: i) A marginal improvement in court quality alone has no effect for many (but not all) combinations of court quality (including the one of high court quality), litigation cost, and level of externality. This suggests that for industrialized countries, whose national courts are typically working efficiently, there are no benefits from an ISDS-based system even if one assumes that panelists on an international tribunal are of higher quality than judges in a national court. For intermediate court quality, however, a marginal increase in court quality improves host country welfare if the production externality in the absence of regulation is large and the firm has a low probability of being entitled to compensation. This result suggests that developing countries may benefit from delegating the decision power over firm-government conflicts to an international tribunal. ii) A higher probability for firms to receive compensation or higher payments when regulation is compensated typically worsens host country welfare, unless the induced increase in firm profits generates substantially more firm entry into the host country. iii) Pareto improvements are possible in some cases through the simultaneous change in two of three of the parameters, for example, when the court quality is high and the externality is at a level where the government inefficiently regulates in the absence of courts. In this case, increasing the compensation parameter in a non-marginal way while lowering the probability of the firm to be compensated in case of regulation can make both sides better off. The switch induces a policy shift from regulation with compensation to no regulation, which is efficient, and the parameter changes indirectly distribute the efficiency gains. I also show, however, that this idea does not always work. For example, when court quality is intermediate and litigation cost are high, the government cannot be made better off, as regulation without compensation is a dominant strategy.

The rest of the paper is organized as follows. In the next section I briefly review related literature. In section $3 \mathrm{I}$ introduce the model, characterize the first best allocation as a benchmark and the equilibrium outcome in the absence of courts (Prop. 1). A generic court is introduced into the analysis in section 4, where I also describe the firm's legal decision (Prop. 2) and the equilibrium policy choice (Prop. 3). This allows me to formally define regulatory chill (Prop. 4 and 5) and to analyze the problem of overregulation, as well as the efficiency of the firm entry decision (Prop. 6). Section 5 focuses on moving the decision power from a national court to an international court (Prop. $7+8$ ). Section 6 concludes. 


\section{Related Literature}

The paper contributes to different types of literature. The paper is closely related to the work by Aisbett et al. (2010a,b), who analyze how changes in the legal extent to which a government does not have to pay compensation in case of regulation (police power carve out, PPCO) affects investment decisions of firms and regulation. In Aisbett et al. (2010a) an optimal PPCO mechanism is studied that leads to efficient regulation and that reduces but does not eliminate the excessive entry problem of firms into host countries. The firm does not initiate litigation but rather a court decides on compensation based on a noisy signal about the possible harm from firm activity. Aisbett et al. (2010b) study in the context of international tribunals based on investment treaties the effect of extending PPCO in an environment where governments are bound by national treatment clauses. The tribunal checks whether a complaint by a firm against regulation without compensation falls within the scope of PPCO. The decision depends on the likelihood of harm from the firm's operation and the strength of international protection in the law. While sharing several common modeling aspects with these two works, the present paper differs in a number of important aspects. First, the present paper formalizes the notion of regulatory chill and studies from that angle the problem of underregulation. The endogeneity of the litigation process is essential for the behavior of firms and governments and allows me to study "frivolous lawsuits". Second, I undertake comparative statics not only with respect to the strength of the protection against harmful regulation, but also focus on the quality of the court in making correct decisions. This aspect is crucial in understanding the different incentives of developing and developed countries to delegate the arbitration power from national courts to international tribunals.

There exists only a small theoretical literature on regulatory chill on the one hand and the effect of ISDS on the other hand. Bagwell and Staiger (2001a,b) argue that concerns over regulatory chill are not valid in the case of trade agreements that deal with regulatory policies relating to traded goods (as opposed to FDI), provided that market access is properly guaranteed. Closely related to the present work is recent research by Kohler and Stähler (2016) who compare the effects of ISDS and national treatment clauses. They argue that ISDS can reduce the holdup problem, but affects inefficiently the regulatory standard setting over time. National treatment creates an entry distortion for domestic firms but may welfare dominate ISDS if the share of domestic firms is large enough. Stähler (2016), Horn and Tangeras (2016), as well as Konrad (2017) analyze optimal ISDS and compensation mechanisms. In Konrad (2017) an ideal ISDS system levels 
the playing field for domestic firms and foreign investors by overcoming a policy failure due to time-consistency, but at the same time aggravates an overinvestment problem. Like this paper, Horn and Tangeras (2016) analyze regulatory chill and show that there is underregulation from a national but not from a world perspective. Unlike the present paper, they analyze a situation of complete information and focus on the optimal design of compensation rules when countries have (dis)similar abilities to commit to their promises to foreign investors ${ }^{2}$

In terms of modeling court challenges, the present work is related to Maggi and Staiger (2011) who analyze the role and mandate of the WTO's Dispute Settlement Body (DSB) for trade conflicts between member countries. Like them, the present paper identifies the incomplete contract framework as the core of the underlying problem that gives courts and arbitration centers a role to play. ${ }^{3}$ The role of imperfect courts is also considered in a more standard closed economy hold up problem by Willington (2013). Like in the present paper, the role of court errors have been the subject of theoretical modeling in the law and economics tradition. For example, Landeo et al. (2006) examine the effects of small court errors in the size of the award on the likelihood of filing and trial, as well as the deterrence effect of punitive damages. Lando and Mungan (2018) evaluate the effects of type- 1 errors by courts (wrongful conviction) and type- 2 errors (wrongful acquittal) and show that type-1 errors can lead to over-deterrence and the chilling of socially benign acts. In the present paper I ago beyond court errors by combining it with a hold up problem, which is common in the context of foreign direct investment.

Finally, the present paper relates to the literature on the determinants of FDI (e.g., Blonigen and Piger, 2011) of which institutional quality in the host country is one important factor. A number of papers has analyzed the role of bilateral investment treaties, and ISDS provisions in particular, for inward FDI. In a series of papers, Busse et al. (2010), Berger et al. (2011, 2013), and Neumayer et al. (2016) find little or no evidence for stricter ISDS provisions to promote FDI, using aggregate FDI data in a gravity-type regression framework. By contrast, Egger and Merlo (2012) - using micro data from the universe of German multinational firms - find a positive and significant effect of BITs on the number flows and FDI magnitude in host countries.

\footnotetext{
${ }^{2}$ There is substantially more work in other social sciences relating to ISDS and regulatory chill, for example, Dietz and Dotzauer (2015) in political science, and Alschner (2013), Bronkers (2015), Kleinheisterkamp (2014) and Pauwelyn (2015) in law. However, case studies and empirical analyses dominate and therefore do not directly speak to the trade off between non-optimal policies and the benefits of foreign investment. There is also a small literature on the lawyers acting as panelists on international tribunals. Panelists on ISDS tribunals have stronger ties to multinational firms from prior work as counselors for investors than judges on national courts (see Gaukrodger and Gordon (2012)).

${ }^{3}$ For a legal perspective on the incompleteness of bilateral investment treaties see Alschner (2013).
} 


\section{The Model}

The world consists of two countries. In each country there exists a continuum of multinational firms that have the option to invest in the other country, called FDI. The firms differ in their sunk investment cost when investing abroad. For simplicity, I assume that firms do not interact economically and therefore the profit maximizing choices are independent. In the following I describe the issue from the home country perspective (the host country), to which one (foreign) firm may enter via FDI.

The firm is risk neutral and wants to maximize its profits. The outside option of not investing at all gives a payoff of zero. FDI requires a fixed cost $F \in[0, \bar{F}]$ which cannot be recovered. Fixed costs are distributed according to a smooth density function $g(F)$ and cumulative density function $G(F)$. Investment in the host country gives the firm a net profit of

$$
\pi_{p}^{n}=\pi_{p}-F
$$

where $\pi_{p}$ is the firm's gross profit, the subscript $p$ refers to a specific government policy, and $n$ refers to net profit. The host government chooses policy $p \in\{0,1\}$, where $p=0$ (also called policy 0) corresponds to no regulation, while $p=1$ stands for regulation (also called policy 1). Regulation of the firm by the host government, for example via permits, rules for compliance with product, environmental or safety standards, affects the firm's gross profit. The binary policy choice reduces the choice set of the government and thereby simplifies the analysis, as the optimal government decision is based on the comparison of two profit levels. Under no regulation $(p=0)$ gross profit is $\pi_{0}>0$, while under regulation $(p=1)$ gross profit is lower

$$
\pi_{1}<\pi_{0}
$$

where $0 \leq \pi_{1}$. The Vattenfall case mentioned in footnote 1 in the introduction represents a specific example of a regulatory policy: The German government terminated the license to operate a nuclear power plant (equivalent to $\pi_{1}=0$ ).

The host country benefits from the presence of a multinational firm. Let $b \geq 0$ be the benefit to the host country, such as the wages paid to local residents or contributions to tax revenues. At the same time the firm's presence may cause an externality $z \geq 0$ on the host country as a byproduct of firm production, when unregulated. The purpose of regulation is to avoid the welfare loss for the host government. There is no loss when the 
firm is regulated $(p=1)$, while the loss is $z>0$ if unregulated $(p=0)$. The government payoff is assumed to be additive in the general benefit from FDI, $b$, and the loss from unregulated externality $z$ :

$$
U=b-(1-p) z=b- \begin{cases}z & \text { if } p=0 \\ 0 & \text { if } p=1 .\end{cases}
$$

It is immediately clear from (3) that the optimal policy for the government ex post (that is, after the firm has made its FDI decision), is to always regulate and choose policy 1.

To discuss the normative implications of the model, I define world welfare $W$ as the sum of firm profits and government welfare (here only for one particular firm):

$$
W=b+\pi_{p}-(1-p) z-F=b-F+ \begin{cases}\pi_{0}-z & \text { if } p=0 \\ \pi_{1} & \text { if } p=1 .\end{cases}
$$

Assuming for the moment that FDI has taken place, and thus $F$ can be ignored, a policy maximizing (4) requires no regulation $(p=0)$ when the externality is sufficiently small, $z<\pi_{0}-\pi_{1}$, and regulation $(p=1)$ when the externality is large $z \geq \pi_{0}-\pi_{1}$. This is summarized in

Proposition 1 (Excessive regulation ex post in the absence of courts). Assume that a firm has entered the host country.

i) In equilibrium the government always regulates and sets policy $p=1$.

ii) The host country policy that maximizes global welfare is given by regulation if the externality is sufficiently large, that is,

$$
\bar{p}=\left\{\begin{array}{ccc}
0 & \text { if } & z<\pi_{0}-\pi_{1} \\
1 & \text { else. }
\end{array}\right.
$$

Proposition 1 shows that in the absence of laws regulating possible compensation for regulation the equilibrium outcome is not efficient. The government regulates too often because it ignores the effect on firm profit. In this case equilibrium profits are lower than what is socially optimal.

Conditional on firm entry and taking (5) into consideration, world welfare under the 
first best regulatory policy amounts to

$$
\bar{W}=b-F+\left\{\begin{array}{cc}
\pi_{0}-z & \text { if } z<\pi_{0}-\pi_{1} \\
\pi_{1} & \text { else }
\end{array}\right.
$$

I now turn to firm entry: In equilibrium the number of entering firms tends to be too small. To see this, note that a firm enters the host country as long as its fixed cost are not too high (given that regulation is chosen ex post):

$$
F \leq \pi_{1}
$$

In the extreme case where the externality is high and the profit under regulation is zero, $\pi_{1}=0$, no FDI takes place for strictly positive fixed cost. By contrast, if the government could commit to the first best policy (5), firms enter the host country whose fixed cost satisfy

$$
F \leq \pi=\left\{\begin{array}{cc}
\pi_{0} & \text { if } z<\pi_{0}-\pi_{1} \\
\pi_{1} & \text { else }
\end{array} .\right.
$$

Turning to the issue of entry efficiency, two statements can be made. First, consider a situation in which the government can commit to an ex post efficient regulatory policy, but cannot set firm entry. Comparison of (7) and (8) shows that entry is efficient when the externality is sufficiently large $z \geq \pi_{0}-\pi_{1}$, but inefficiently low when the externality is below $\pi_{0}-\pi_{1}$. In the former case firms with fixed cost up to $\pi_{1}$ enter in equilibrium, which is efficient, while in the latter case firms with fixed cost up to $\pi_{0}$ should enter, but some of them do not.

Second, when taking the social benefits $b$ and social costs of FDI $z$ into account, entry is typically too low. Entry is not only insufficient when regulation is excessive. Suppose instead that regulation is first best because $z>\pi_{0}-\pi_{1}$. Then, by inspection of the second line in condition (6), entry of a firm is socially beneficial if $b+\pi_{1} \geq F$, while in equilibrium entry occurs as long as $\pi_{1} \geq F$ (see (7)). Hence, there is insufficient entry for strictly positive benefits from FDI, $b>0$, and a sufficient wide distribution of fixed $\operatorname{cost} F$, so that for at least one firm the condition $b+\pi_{1} \geq F>\pi_{1}$ holds. The latter is satisfied for $\bar{F}>\pi_{1}$. The "entry gap" in terms of fixed cost thresholds, defined as the difference between $\left(b+\pi_{1}\right)$ and $\pi_{1}$ equals $b$, and rises with the social benefit from foreign direct investment. The entry gap in terms of the mass of firms that are kept out of the host country amounts to $G\left(b+\pi_{1}\right)-G\left(\pi_{1}\right)$. 
Furthermore, the entry gap is larger when regulation is excessive (and not first best). For $z<\pi_{0}-\pi_{1}$, entry should occur as long as $b+\pi_{0}-z \geq F$ (first line of (6)). The fixed cost entry threshold in equilibrium is still $\pi_{1}$. Therefore the entry gap in terms of fixed cost now is $\left(b+\pi_{0}-z\right)-\pi_{1}$, which by the assumption of excessive regulation is greater than in the situation with optimal regulation, where it was $b$. The entry gap in terms of mass of firms is $G\left(b+\pi_{0}-z\right)-G\left(\pi_{1}\right)$, and therefore more firms are kept out given a wide enough support of fixed cost $\bar{F}>\pi_{0}-z-\pi_{1}$.

In the following I assume $b>0$ and $\bar{F}>\pi_{0}-z-\pi_{1}$, so that there is always insufficient entry, and the entry gap is larger under excessive regulation. Proposition 1 suggests that laws which safeguard the firm against "excessive" regulation could be beneficial. This motivates the introduction of laws against regulation without compensation that are enforced by courts.

\section{Court challenges and regulatory chill}

A law against indirect expropriation may help in overcoming the excessive regulation problem. Often, however, the law is vague in terms of specifying the circumstances when compensation should be paid. I capture this by a random shock that determines the state of nature. In practice court challenges by firms, successful and unsuccessful ones, are observed, as documented in Unctad (2018). This suggests that uncertainty about the success of a lawsuit plays a role.

\subsection{Court challenges against regulation without compensation}

After the FDI decision, nature chooses state $s \in\{0,1\}$. The state of nature determines whether or not a regulatory action by the government that affects the firm negatively requires compensation payment according to the law. While the law spells out compensatable regulations, identifying conditions under which compensation is to be paid ex post is difficult. I assume that the firm and host government know whether a compensation payment is legitimate or not, which depends on the state of nature. In state $s=0$ no compensation payment is necessary, which occurs with probability $1-q$, while $s=1$ means compensation must be paid according to the law. The latter state happens with probability $q \in[0,1]$. By assumption, the state is observable to the firm and the host government, but is not contractible, as it is not observable to outsiders such as a court. From an ex ante perspective, the firm is uncertain as to whether regulation by the government ex post allows the firm to rightfully claim compensation. The parameter $1-q$ 
can be interpreted as a measure of "carve out", the extent to which there are situations in which the firm does not have to be compensated when facing harmful regulation, while $q$ is a measure of the protection of the firm (see Aisbett et al. 2010a, 2010b for their modeling of carve outs). If $q=1$ or $q=0$, the law is clear cut and the firm is always or never to be compensated when regulation takes place.

More generally, the stochastic carve out rule represents a way to capture the vagueness of the law, in particular, international investment treaties that define compensatable conditions, which need to be interpreted in actual situations. The quote from a bilateral investment treaty at the beginning of this paper gives an example for the vagueness of defining indirect expropriation by referring to the exception of rare circumstances that are not specified. In addition, even the reference to health and safety objectives leaves room for interpretation, as strategically designed industrial policies that aim to protect domestic producers may be disguised as policies that foster public welfare objectives. Courts therefore have discretionary power in deciding cases brought to them, and this makes the outcome of legal proceedings uncertain for foreign investors and host governments. While this may be unavoidable in principle, the law can be more or less vague however, and make the case for compensation stronger or weaker ex ante, for example, by (not) enumerating the circumstances in which compensation is to be paid. The parameter $q$ captures that degree of ex ante clarity of the law in favor of compensation to the firm.

Compensation is assumed to be proportional to the loss of the firm from regulation $\beta\left(\pi_{0}-\pi_{1}\right)$, where $\beta \leq 1$ is a parameter of the law. A value of one means full compensation, a value of $\beta$ strictly less than 1 means that compensation is not complete. There is no overcompensation $\beta>1$, or fines on top of compensation payments, such that the government would pay more than what the firm receives (and the difference going to a third party). As for notation, I use $m \in\left\{0, \beta\left(\pi_{0}-\pi_{1}\right)\right\}$ to describe the amount of compensation ("money") paid to the firm, which is either zero or proportional to the firm's loss of profit.

The timing of events is:

1. Firm decides on FDI. If no FDI, the game ends, otherwise the game continues with

2. Nature draws state $s \in\{0,1\}$, which is observed by firm and government, but not by court

3. Government announces its regulatory policy $p \in\{0,1\}$, and compensation $m \in$ $\left\{0, \beta\left(\pi_{0}-\pi_{1}\right)\right\}$ in case regulation is chosen. The game ends if the host government chooses either regulation $p=1$ with compensation $m=\beta\left(\pi_{0}-\pi_{1}\right)$ or no regulation 
$p=0$. Then the announced policy in stage 3 is implemented. If, by contrast, the host government chooses regulation $p=1$ without compensation $m=0$, the game continues with the next stage

4. The firm decides whether to challenge the government in court. If no challenge, the regulatory policy $p=1$ without compensation $(m=0)$ is implemented. If challenged, then the game continues with

5. Court decides on whether compensation needs to be paid.

In the last stage the court correctly identifies the state of nature with probability $\theta \in[0,1)$. The parameter $\theta$ is a measure for the institutional quality of the court system. The higher the value of $\theta$, the better is the quality of the court. To illustrate the mechanism, assume that the state is $s=1$ and the firm goes to court. If the court believes the state is $s=1$ and rules accordingly, the host government is forced to paying $m=\beta\left(\pi_{0}-\pi_{1}\right)$ to the firm. When the court does make the wrong decision, however, believing the state is $s=0$, then no payment of compensation is forced $(m=0)$. In summary, the court may err in both directions, forcing compensation payment when it should not, as well as not ruling in favor compensation payments even though it should. The latter feature shares similarities with Lando and Mungan (2018) who discuss the role of type- 1 and type-2 errors for deterrence of bad acts in a theory of legal procedure.

My setup implies that the likelihood of the court erring in the direction of mistakenly assessing a carve out is the same as the probability of the court erring in the other direction by wrongly assessing a no carve out. In that way, I adopt a neutral position in the debate between those who feel that courts may be biased towards host governments and others like NGOs who believe that courts and ISDS panels in particular favor multinational firms. A further assumption in my setup is that the probability of an error by the court is independent of the size of the externality. While it is conceivable that the court expands more resources when the stakes are high (as measured by $z$ ), and may therefore be more likely to identify the state of nature, the key underlying economic problem remains, as long as the court may err.

I assume that a challenge in court is costly to the loser of the case, where the loser is determined by the court's decision. If the government is forced to pay compensation, it is the loser. Otherwise it is the firm that has to pay the court cost, also called litigation cost. Losing a court case $\operatorname{costs} c \geq 0$, which I assume to be wasteful from a global welfare perspective. Because courts may err, the payment of court costs may be born by the "wrong" side. This implication is unavoidable, however, because courts do not observe 
the state of nature. ${ }^{4}$ The cost of losing in court is an important parameter of the model. In particular, the size of the cost $c$ relative to the compensation payment matters,

$$
c \gtreqless \beta\left(\pi_{0}-\pi_{1}\right) .
$$

When $c$ is less then the compensation payment, then (9) implies $c /\left(c+\beta\left(\pi_{0}-\pi_{1}\right)\right)<0.5$. I call this the case of "low litigation cost". The reverse relationship holds, when the inequality in (9) is reversed, which is called "high litigation cost".

It is now straightforward to see that a perfect court - which always correctly identified state $s$ - would make legal challenges obsolete: Either because the firm anticipates correctly to lose its case (which is costly), or because a government that does not pay compensation would be successfully challenged subsequently and could avoid paying the court cost by paying compensation right away.

The option to challenge in court affects the government's incentive to pick one policy over the other. The welfare effects of this option are a priori unclear. Court challenges could reduce excessive government regulation, but may also allow strategic behavior by the firm in the form of what will be called frivolous lawsuits, that is lawsuits in state $s=0$

The above game is solved from the back, as usual. I begin with an analysis of stages 3 and 4 . Stage 5 is mechanical, as the court's decision can be directly represented by a probabilistic outcome.

\subsection{Stages 3 and 4: Policy announcement and court challenge}

Stage 4. By assumption, the announced policy is implemented and no court case develops if the government chooses either no regulation or regulation with compensation. In the former case the firm's operating profit is $\pi_{0}$, while under the latter it is $\pi_{1}+\beta\left(\pi_{0}-\pi_{1}\right)$. The government obtains utility $b-z$ and $b-\beta\left(\pi_{0}-\pi_{1}\right)$, respectively. If the government announced regulation policy $p=1$ without compensation in stage 3 , the firm faces in stage 4 the decision whether to challenge in court or not.

\footnotetext{
${ }^{4}$ Cost of litigation in a ISDS system may be quite substantial. Gaukrodger and Gordon (2012) report that expenses are mostly for legal counsels. In the arbitration system under the auspices of the World Bank (ICSID) arbitrators are paid around 3,000 USD per day. Depending on the legal frame cost of litigation may be left to the international panel's final award decision (as under ICSID) or to the "unsuccessful party" (as under the United Nations system UNCITRAL). The latter is in line with the present paper. While in public international law typically parties pay their own way, recently a trend towards shifting costs has been observed. What matters for the formal analysis is that losing a court case is costly, either because the loser pays all court cost, or because meeting in court in the first place is costly.
} 
a) The firm files a lawsuit in state $s=1$ if and only if

$$
\pi(\text { chall. } \mid s=1)=\theta\left[\pi_{1}+\beta\left(\pi_{0}-\pi_{1}\right)\right]+(1-\theta)\left[\pi_{1}-c\right] \geq \pi_{1}=\pi(\text { no chall. } \mid s=1) .
$$

The first term on the left hand side of the inequality gives the expected profit when the court correctly identifies the state, implying a compensation payment to the firm and no court cost, while the second term is the firm's profit when losing in court. The two outcomes are weighted by the probability of the court's decision making. The right hand side of the inequality represents the sure payoff when no challenge in court is filed. The inequality can be rewritten as

$$
\theta \geq \theta^{*}:=\frac{c}{c+\beta\left(\pi_{0}-\pi_{1}\right)}
$$

In other words, the firm litigates in state $s=1$ if the probability of winning in court is sufficiently high. Note that $\theta^{*}$ may be greater or less than one half, as discussed above in the context of (9). Under the assumption of small litigation cost relative to the compensation payment, $\theta^{*}$ is less than 0.5 .

b) Now consider the case where the state is $s=0$. The firm litigates if and only if

$$
\pi(\text { chall. } \mid s=0)=\theta\left[\pi_{1}-c\right]+(1-\theta)\left[\pi_{1}+\beta\left(\pi_{0}-\pi_{1}\right)\right] \geq \pi_{1}=\pi(\text { no chall. } \mid s=0) .
$$

Again the firm trades off the probability weighted payoffs under the legal challenge against the sure payoff under no challenge. The condition is equivalent to

$$
\theta \leq 1-\theta^{*}=\frac{\beta\left(\pi_{0}-\pi_{1}\right)}{c+\beta\left(\pi_{0}-\pi_{1}\right)} .
$$

In other words, the firm litigates if the court is sufficiently likely to err in case the law intends no compensation to the firm. To summarize:

Proposition 2 (court challenges by the firm): a) The firm goes to court when facing regulation without compensation in state $s=1$ if $\theta \geq \theta^{*}$, and in state $s=0$ if $\theta \leq$ $1-\theta^{*}$. b) Assume the court is of medium quality: $\theta \in\left[\min \left\{\theta^{*}, 1-\theta^{*}\right\}, \max \left\{\theta^{*}, 1-\theta^{*}\right\}\right]$. When $\theta^{*}<0.5$, and thus litigation costs are low, the firm litigates in both states of nature, while for high litigation cost $\theta^{*}>0.5$, the firm never litigates.

Proposition 2 implies that depending on the quality of the court and size of litigation cost different types of regimes can be defined. If $\theta \geq \max \left\{\theta^{*}, 1-\theta^{*}\right\}$, meaning the 
court is of high quality, the firm challenges in state $s=1$ but not in $s=0$. Court challenges are therefore always "rightful". When institutional quality of the court is in the medium range however, rightful and frivolous lawsuits coexist when litigation cost are low, while litigation is completely suppressed when cost are sufficiently high and therefore legitimate claims to compensation are not filed. Finally, when court quality is sufficiently low, $\theta<\min \left\{\theta^{*}, 1-\theta^{*}\right\}$, there are only frivolous lawsuits: the firm litigates in state $s=0$, but not in state $s=1$. Table 1 shows various regimes as function of litigation cost and court quality.

\section{Insert Table 1 about here}

Stage 3. I now turn to stage 3 in which the host country government needs to announce its policy. It can choose among three options: no regulation and no compensation $(p, m)=(0,0)$, regulation without compensation $(p, m)=(1,0)$, and regulation with compensation $(p, m)=\left(1, \beta\left(\pi_{0}-\pi_{1}\right)\right)$. Depending on the firm's litigation decision and state of nature, the possible payoffs for the host country are:

$$
U=\left\{\begin{array}{clc}
b-z & \text { if } & p=0 \\
b-\beta\left(\pi_{0}-\pi_{1}\right) & \text { if } & p=1 \wedge m=\beta\left(\pi_{0}-\pi_{1}\right) \\
b & \text { if } & p=1 \wedge m=0 \wedge \text { nolawsuit } \\
b-\theta\left[\beta\left(\pi_{0}-\pi_{1}\right)+c\right] & \text { if } & p=1 \wedge m=0 \wedge \text { lawsuit, } s=1 \\
b-(1-\theta)\left[\beta\left(\pi_{0}-\pi_{1}\right)+c\right] & \text { if } & p=1 \wedge m=0 \wedge \text { lawsuit, } s=0 .
\end{array}\right.
$$

In the case of litigation the government risks losing the compensation payment and the court cost. It is useful to define this amount as

$$
A:=\beta\left(\pi_{0}-\pi_{1}\right)+c
$$

and hence $1-\theta^{*}=\beta\left(\pi_{0}-\pi_{1}\right) / A$ and $\theta^{*}=c / A$. In its decision the government anticipates correctly the firm's decision in stage 4 . The following Proposition characterizes the equilibrium outcome in stage 3 .

Proposition 3 (Regulation in presence of courts). In stage 3 the government's announced policy depends on the quality of the court:

- The quality of the court is high, $\theta \geq \max \left\{\theta^{*}, 1-\theta^{*}\right\}$ : In state $s=1$, the government 
announces

$$
(p, m)=\left\{\begin{array}{ccc}
(0,0) & \text { if } & z<\beta\left(\pi_{0}-\pi_{1}\right) \\
\left(1, \beta\left(\pi_{0}-\pi_{1}\right)\right) & \text { if } & z \geq \beta\left(\pi_{0}-\pi_{1}\right)
\end{array}\right.
$$

and in state $s=0$, the government announces

$$
(p, m)=(1,0)
$$

- The quality of the court is intermediate $\theta \in\left[\min \left\{\theta^{*}, 1-\theta^{*}\right\}, \max \left\{\theta^{*}, 1-\theta^{*}\right\}\right]$ : When cost of litigation is high, the government announces a policy of regulation without compensation (1,0). When cost of litigation is low, however, in state $s=1$, the government announces

$$
(p, m)=\left\{\begin{array}{lll}
(0,0) & \text { if } \quad z<\theta A \\
(1,0) & \text { if } \quad z \geq \theta A
\end{array}\right.
$$

while in state $s=0$ the government announces

$$
(p, m)=\left\{\begin{array}{lll}
(0,0) & \text { if } \quad & z<(1-\theta) A \\
(1,0) & \text { if } \quad z \geq(1-\theta) A
\end{array}\right.
$$

- The quality of the court is low $\theta<\min \left\{\theta^{*}, 1-\theta^{*}\right\}$ : In state $s=1$ the government regulates without compensation, as in (15), regardless of litigation cost. In state $s=0$, by contrast, and regardless of litigation cost, the government chooses a policy as in (14).

Proof: When court quality is high, the firm goes to court in state $s=1$ but not when $s=0$ (see Prop. 2). Therefore in the latter case the host government has no benefit from paying compensation and always regulates (see (15)). In state $s=1$, however, taking the risk of litigation is too high for the government because the court detects the state of nature (which requires compensation) with high probability. Thus the government effectively compares the loss from no regulation (first line in (12)) with regulation plus compensation payment (second line in (12)), and ends up with a decision shown in (14). Regulation with compensation is optimal for the government when the externality is large enough.

Next, consider the case of intermediate court quality. When litigation cost are high, 
there is no risk of a lawsuit (see Table 1), and hence the government chooses regulation to avoid the externality (Prop. 2). When litigation cost are low, and assuming $s=0$, the government compares the payoffs under no regulation, regulation with compensation, as before, and regulation without compensation (and therefore litigation, last line in (12)). Under low litigation cost, $\theta<1-\theta^{*}$, paying compensation in case of regulation is worse than risking the lawsuit. Effectively the government compares only the first and the last option, which depends on the size of the externality $z$ and the expected loss $(1-\theta) A$, see (17). By contrast, when $s=1$ the reasoning is identical except for the probability that the government loses its case when regulating without compensation. Hence conditions (16) and (17) are structurally the same.

Finally, when court quality is low, the firm always litigates in state $s=0$ because the bad court quality gives high expected profits from legal recourse, but does not litigate in state $s=1$. In the latter case, there is no downside for the government from regulating, and no need to pay compensation. In state $s=0$, things are different. First, I can rule out regulation without compensation regardless of litigation cost. To see this, consider first low litigation $\operatorname{cost} \theta^{*}=c / A<0.5$. Because court quality is low, $\theta<\theta^{*}$, the condition for regulation without compensation to dominate regulation with compensation is $\theta>$ $c / A$, which is inconsistent with the previous conditions for this case. Next, consider high litigation cost, $\theta^{*}=c / A>0.5$, together with low court quality $\theta<1-\theta^{*}=1-c / A<0.5$. Again the condition for policy pair $(1,0)$ to dominate $\left(1, \beta\left(\pi_{0}-\pi_{1}\right)\right)$ is $\theta>c / A$, which is impossible because $\theta$ cannot be higher and less than 0.5 at the same time. This leaves only the option to not regulate or regulate with compensation, which is driven by the externality $z$ relative to the compensation payment, as shown in (14). q.e.d.

Proposition 3 is illustrated in Figure 1 for the case of low litigation cost (see the note at the bottom of the graph for high litigation cost). While the qualitative structure of the graph is very similar in both states of nature, Figure 1 shows that the policy choices tend to reverse. Low court quality leads to regulation without compensation when the firm is entitled to compensation, while when it is not, the government does not regulate or pays compensation when regulating.

\section{Insert Figure 1 about here}

It can also be seen that if the court is of intermediate quality, the host country never pays compensation, see (16)-(17), and may or may not regulate, depending on parameters. If the court is of high quality however, compensation may be paid, namely in state $s=1$, when the firm is entitled to compensation and with sufficiently high externality $z$. High 
court efficiency means that offering compensation right away is preferred over the chance of losing in court. Choosing no regulation $(p=0)$ is not an attractive alternative if the externality is large. Note, however, that compensation payments are sometimes chosen even when court quality is low. Unlike the case of high court quality, it is now in state $s=0$ that the high probability of the court erring in favor of the firm gives "perverse" incentives for the government to offer compensation if the externality is large enough even though the firm is not entitled to compensation.

\subsection{Overregulation and Regulatory Chill}

Comparing Propositions 1 and 3 allows me to assess whether ex post there exists overregulation ( $p=0$ efficient from a world welfare perspective, but $p=1$ chosen by the government) or underregulation ( $p=1$ welfare maximizing, but $p=0$ chosen). Recall from Prop. 1 that compensation payments are not relevant for assessing first best policies (for given FDI levels), because they represent pure transfers among agents.

Proposition 4 (Overregulation ex post). From a world welfare perspective the host government policy is inefficient ex post only due to excessive regulation, not underregulation. When $\beta<1$, overregulation occurs for some parameter values regardless of the quality of the court.

Proof: Consider first the possibility of underregulation, that is $\bar{p}=1$ is optimal, but $p=0$ is chosen in equilibrium.

- This cannot happen when court quality is high. No regulation (policy 0) is chosen only when $z<\beta\left(\pi_{0}-\pi_{1}\right)$, which is efficient (see Prop. 1) because the externality is below $\pi_{0}-\pi_{1}$.

- In the case of intermediate court quality, the government always regulates in case of high litigation cost, and hence no underregulation problem arises. When litigation cost are low, no regulation $(p=0)$ is chosen in state $s=1$ when $z<\theta\left[\beta\left(\pi_{0}-\right.\right.$ $\left.\left.\pi_{1}\right)+c\right]=\theta A$. However, by assumption of intermediate court quality (and low litigation cost) $\pi_{0}-\pi_{1}>\theta\left[\beta\left(\pi_{0}-\pi_{1}\right)+c\right]=\theta A$. Together the two conditions imply $z<\left(\pi_{0}-\pi_{1}\right)$, which is the condition for no regulation to be first best. In state $s=0$ no regulation occurs for $z<(1-\theta) A \leq\left(1-\theta^{*}\right) A=\beta\left(\pi_{0}-\pi_{1}\right)<\left(\pi_{0}-\pi_{1}\right)$, which is efficient.

- In case of low court quality, an underregulation problem can only arise in state $s=0$ when $z<\beta\left(\pi_{0}-\pi_{1}\right)$, but again no regulation is efficient in that case. 
To prove the second part of the Proposition, I identify the conditions under which no regulation $(\bar{p}=0)$ is optimal from a world welfare perspective, but regulation $(p=1)$ is chosen in equilibrium. The former requires $z<\pi_{0}-\pi_{1}$.

- High court quality: In state $s=1$ overregulation occurs if $z \in\left[\beta\left(\pi_{0}-\pi_{1}\right),\left(\pi_{0}-\pi_{1}\right)\right]$, that is $p=1$ is chosen in equilibrium (see (14)), but is not efficient because the externality is small. The set of values of the externality is non-empty if $\beta<1$. In state $s=0$ the government always regulates which is inefficient if $z<\pi_{0}-\pi_{1}$.

- Medium court quality: In case of high litigation cost, regulation is excessive whenever $z<\pi_{0}-\pi_{1}$. However, even for low litigation cost there is overregulation. In state $s=1$, too much regulation is observed if $z \in\left[\theta A, \pi_{0}-\pi_{1}\right]$, where $\theta A \geq$ $\beta\left(\pi_{0}-\pi_{1}\right)$ and in state $s=0$ if $z \in\left[(1-\theta) A, \pi_{0}-\pi_{1}\right]$, where $(1-\theta) A \leq \beta\left(\pi_{0}-\pi_{1}\right)$.

- Low court quality: Mirrows the case of high court quality. Overregulation occurs in state $s=1$ when the externality is low, and also in state $s=0$ when the externality lies between compensation payment and efficiency threshold. This completes the proof.

Proposition 4 is intuitive given that Proposition 3 establishes that a policy of no regulation $p=0$ is chosen only when $z$ is relatively small. But efficiency dictates no regulation when the externality is small, and in fact the efficient cutoff for no regulation is higher than the one chosen in equilibrium as long as $\beta<1$. In addition, it is interesting to note that a more efficient court does not guarantee efficiency. Even when the court always correctly identifies the state of nature, $\theta=1$, there is an inefficiency when $s=0$, and also for $s=1$, as long as compensation payments do not fully amount to the loss in profits, that is, $\beta<1$. Higher values of $\beta$ make the range of $z$ for which inefficiencies occur smaller however.

I now turn to the issue of regulatory chill. From a world welfare perspective there is no underregulation, as shown in Prop. 4. The result suggests that the notion of regulatory chill, according to which a host government is deterred from legitimate regulation in face of a possible lawsuit, is ill-conceived. However, one may ask whether there is regulatory chill from a national welfare viewpoint. To answer this question I first define regulatory chill to satisfy the following three conditions

1. the firm challenges a policy of regulation without compensation in stage 4

2. the government prefers regulation over no regulation if the firm did not file a lawsuit in the presence of regulation without compensation, and 
3. the host government chooses no regulation instead of regulation when it anticipates a legal challenge in stage 4 .

At first glance, the last condition appears to make little sense because the government could compensate the firm if it feels that avoiding the loss from missing regulation is so large. This reasoning is valid when the state of nature is $s=1$ because the firm should and would be compensated if the court could perfectly observe the state of nature. However, in state $s=0$ the logic is different because compensation payments should not be paid.

Proposition 5 (Regulatory chill). Assume low litigation cost. From a host country perspective there exists regulatory chill in state $s=0$ if the court is of intermediate quality and the externality is not too large $z<(1-\theta) A$.

Proof: The assumptions on litigation cost and court quality imply that the firm always challenges a policy of regulation without compensation (see Prop. 2). The first property of regulatory chill therefore holds. The second one is always fulfilled when the firm does not litigate, as the situation is equivalent to the case without court (see Prop. 1). The third property is also fulfilled because the host government does not regulate when the conditions provided in the Proposition are met (see Prop. 3, condition (17)). q.e.d.

Proposition 5 suggests that in the present framework the claim that governments can always regulate and compensate if the externality is large enough, while formally correct, is not fully convincing. While the host government could regulate with compensation it seems inappropriate in a situation where the firm should not be compensated. It is thus the case of a frivolous lawsuit due to imperfect courts that leads to regulatory chill from a domestic policy perspective.

\subsection{Stage 1: Firm Entry}

I now move to stage 1 in which the firm decides on entry into the host country before the state of nature is determined. The firm anticipates correctly the subsequent decisions and therefore enters the host country if its fixed cost are no more than the expected profit: $F \leq \pi^{e}$. To proceed with the analysis it is useful to summarize the payoffs $(U, \pi, W)$ conditional on $s$, from which the expected payoffs in stage 1 can be computed. Conditional on firm entry, the expected firm payoff depends on court quality and can be derived from the probability weighted payoffs in the two situations depending on $s$ :

- High court quality $\theta \geq \max \left\{\theta^{*}, 1-\theta^{*}\right\}$ : The equilibrium policy is found in (14) and (15) and implies that in state $s=0$ there is always regulation without compensation, 
but in the other state either regulation with compensation or no regulation occurs depending on the size of the externality

$$
\pi^{e}=(1-q) \pi_{1}+q \cdot\left\{\begin{array}{ccc}
\pi_{0} & \text { if } & z<\beta\left(\pi_{0}-\pi_{1}\right) \\
\left(\pi_{1}+\beta\left(\pi_{0}-\pi_{1}\right)\right) & \text { if } & z \geq \beta\left(\pi_{0}-\pi_{1}\right)
\end{array}\right.
$$

- Intermediate court quality: Under high litigation costs the firm never challenges even though facing regulation. The expected firm profit is

$$
\pi^{e}=\pi_{1}
$$

When litigation costs are low, the case is more involved because the firm always litigates when facing regulation without compensation. The relevant policy chosen by the host government is given in (16) and (17). There are two critical thresholds for the externality, $\theta A$ and $(1-\theta) A$, which represent the expected loss of the government when losing in court

$$
\pi^{e}=\left\{\begin{array}{ccc}
\pi_{0} & \text { if } & z<(1-\theta) A \\
\pi_{1}+[q+(1-q)(1-\theta) \beta]\left(\pi_{0}-\pi_{1}\right)-(1-q) \theta c & \text { if } & z \in[(1-\theta) A, \theta A] \\
\pi_{1}+[q \theta+(1-q)(1-\theta)] \beta\left(\pi_{0}-\pi_{1}\right)-[(1-q) \theta+(1-\theta) q] c & \text { if } & z \geq \theta A
\end{array}\right.
$$

In the first line, the government does not regulate in both states of nature when $z$ is sufficiently small. Hence the firm obtains $\pi_{0}$. For intermediate levels of the externality, the second line represents the situation where the government chooses regulation without compensation in state $s=0$, but no regulation in state $s=1$. The firm litigates in the former case. The firm gets more than profit $\pi_{1}$ in state $s=1$, which occurs with probability $q$, and in state $s=0$ (probability $1-q$ ) when the court misjudges the situation and awards compensation. However when the court correctly identifies the state, the firm must pay court cost which amounts to $(1-q) \theta c$ in expected terms. By contrast, when the externality is high (third line in 20), the firm always litigates against regulation without compensation. The host government never pays compensation. In this case the firm gets compensation in state $s=1$ when the court correctly identifies the state, and in state $s=0$ when the court misjudges. Court cost must be paid by the firm in the opposite cases, which in expected terms amounts to the last term in the last line of (20). 
- Low court quality: This is the flip side of high court quality (see Prop. 3).

$$
\pi^{e}=q \pi_{1}+(1-q) \cdot\left\{\begin{array}{ccc}
\pi_{0} & \text { if } & z<\beta\left(\pi_{0}-\pi_{1}\right) \\
\left(\pi_{1}+\beta\left(\pi_{0}-\pi_{1}\right)\right) & \text { if } & z \geq \beta\left(\pi_{0}-\pi_{1}\right)
\end{array}\right.
$$

It is interesting to note that the legal system tends to push the firm to too much entry when the externality is so high that in the first best regulation would be the efficient policy, and thus the firm's profit would be $\pi_{1}$. In (19) to (21) the firm obtains profits above $\pi_{1}$.

The above considerations ignore fixed cost and social benefits from foreign direct investment. To analyze the efficiency of firm entry, note that the expected firm payoff defines the cutoff level for firm entry, because at $F^{*}=\pi^{e}$ the firm breaks even. Firms with $F \leq F^{*}$ enter while those with higher fixed cost stay out. The number of entering firms is $N^{*}=G\left(F^{*}\right)=\int_{0}^{\pi^{e}} g(F) d F$. For the following result it is useful to recall the conditions for efficient entry (see section 3 ). The fixed cost threshold associated with efficient entry is $b+\pi_{0}-z$ if the externality is small $\left(z<\pi_{0}-\pi_{1}\right)$, and $b+\pi_{1}$ when the externality is above that level.

Proposition 6 (inefficient firm entry). Assume $b \geq z$, so that FDI is not harmful for the host country in the absence of regulation. Firm entry is inefficiently low when $b>z$, except for the case where entry is is efficient, namely when at the same time $b=z$,

Proof. The proof is structured along the level of court quality.

- Consider first the case in which court quality is high. Assume that the externality is small, i.e. $z<\beta\left(\pi_{0}-\pi_{1}\right)$. Entry is inefficiently low because $F=\pi^{e}=(1-q) \pi_{1}+q \pi_{0}$ is less than $b+\pi_{0}-z=\hat{F}$ under the assumption $b \geq z$. A similar argument holds when the externality is intermediate, $\left(\pi_{0}-\pi_{1}\right)>z \geq \beta\left(\pi_{0}-\pi_{1}\right)$, because the marginal firm entering in equilibrium has an expected profit below $\pi_{0}$ (see second line of (18)), while the efficient level is still characterized by something at least as high as $\pi_{0}$. Finally, consider the case of a high externality, $\left(\pi_{0}-\pi_{1}\right)<z$. Entry is still too low because $F=\pi^{e}=\pi_{1}+\beta q\left(\pi_{0}-\pi_{1}\right)<b+\pi_{1}=\hat{F}$.

- Next, consider the case of intermediate court quality. When litigation costs are high, entry falls short because expected profits are $\pi_{1}$, which is below the efficient threshold regardless of the externality level. When litigation costs are low, from (20) it is clear that the marginal firm's expected profit depends on the size of the 
externality. Assume for the moment that the cutoff for the change in the first best policy $z=\pi_{0}-\pi_{1}$ falls in the highest range $z>\theta A$. Then the marginal firm that enters under a low externality $z<(1-\theta) A$ is $\pi_{0}$, which is less or equal to $b+\pi_{0}-z=\hat{F}$, and exactly equal when $b=z$. When $z \in[(1-\theta) A, \theta A]$ the efficient entry level is unchanged but $\pi^{e} \in\left(\pi_{1}, \pi_{0}\right)$, as evident from the second line of (20). The same argument holds in the highest externality range $z>\theta A$, as long as $z<\pi_{0}-\pi_{1}$. Finally, when $z>\pi_{0}-\pi_{1}$ and thus $z>\theta A$, the first best threshold is $b+\pi_{1}=\hat{F}$, while for the marginal firm that enters $\pi^{e} \in\left(\pi_{1}, \pi_{0}\right)$. Entry is inefficient because $b+\pi_{1}=\hat{F} \geq z+\pi_{1}>\left(\pi_{0}-\pi_{1}\right)+\pi_{1}=\pi_{0}>\pi^{e}$. To complete this part of the proof I need to show that the initial condition $\pi_{0}-\pi_{1}>\theta A$ holds. The condition is satisfied because for the highest possible $\theta$, which is in the case of intermediate court quality (and low court cost) is $1-\theta^{*}, \theta A \leq\left(1-\theta^{*}\right) A=\beta\left(\pi_{0}-\pi_{1}\right) \leq \pi_{0}-\pi_{1}$.

- Finally, consider the case of low court quality. The proof runs as in case of high court quality because (18) and (21) are qualitatively identical except for the exchange of the probabilities $q$ and 1 -q.q.e.d.

Proposition 6 makes a clear statement whenever the host country strictly benefits from FDI in case of no regulation. The case of $b=z$ is special and is consistent with efficient entry if at the same time the court quality is low and the externality is sufficiently small $z<(1-\theta) A$. There is never excess entry however. This insight suggests that entry should be encouraged in almost all cases, which could be done via an entry subsidy. In the present framework an alternative instrument is to adjust $q$, that is changing the degree of investor protection or carve out. I compute the level of $q$ that induces efficient entry, which is obtained by equating the expected profit from entry to the efficient one. It is easy to see that $q$ needs to be high, that is a small carve out. In fact, the $q$ that solves the indifference condition satisfies

$$
1 \leq q^{e f f}=\left\{\begin{array}{ccc}
\frac{b-z}{\pi_{0}-\pi_{1}}+1 & \text { if } & z<\beta\left(\pi_{0}-\pi_{1}\right) \\
\frac{b-z}{\beta\left(\pi_{0}-\pi_{1}\right)}+1 & \text { if } & z \in\left[\beta\left(\pi_{0}-\pi_{1}\right),\left(\pi_{0}-\pi_{1}\right)\right] \\
\frac{b}{\beta\left(\pi_{0}-\pi_{1}\right)} & \text { if } & z \geq \pi_{0}-\pi_{1}
\end{array}\right.
$$

The two threshold levels for the externality that lead to the three ranges in (22) reflect the switch in equilibrium policy at $z=\beta\left(\pi_{0}-\pi_{1}\right)$ and the switch in welfare optimal regulation at $z=\left(\pi_{0}-\pi_{1}\right)$. If $q$ is limited to be between 0 and 1 , the best policy is to set $q$ equal to 1 . This avoids the problem that the optimal $q$ should otherwise depend on $z$. 


\section{The effect of ISDS}

In the previous section I described a generic court, without specific reference to international law. I now consider the effects of moving the decision power for legal conflicts from a domestic to an international court, like an investor-state dispute settlement panel (ISDS) based on an international investment treaty. An ISDS based international panel may differ from a national court in three dimensions. First, an international court may be more "professional" or of higher quality than a national court. The quality of court decisions appears to be the factor underlying the proposal to have professional judges rather than an expert panel in international arbitration, as considered in the Canada-EU trade agreement CETA. Panel experts may have a bias towards firms because panelist on an international tribunal are often drawn from private law firms with more working relationships to firms. Gaukrodger and Gordon (2012) report that 50\% of ISDS arbitrators acted as counsels for investors in other ISDS cases, whereas only $10 \%$ of arbitrators worked as counsels for governments previously. ${ }^{5}$ Unlike legal systems in most highly developed countries, courts in politically unstable or corrupt countries may not be able to guarantee a neutral legal setting. Shifting the decision power to ISDS may remedy this problem. In the formal model I capture a differential court quality by the parameter $\theta$. Higher values mean better quality. ${ }^{6}$

A second possible difference between a national court and international tribunals is the scope of compensation in case of regulation. An international investment treaty typically guarantees the full value of the investment in case of nationalization. ${ }^{7}$ By comparison national law may have a narrower scope and be thus less beneficial to the firm. In terms of the above model the size of compensation is captured by the parameter $\beta$. A higher value of $\beta$ means more compensation. Note that a higher $\beta$ could be interpreted as higher present value. For instance, if the scope of the compensation in the national legal system is the same as the one signed in an international investment treaty, processing the claim

\footnotetext{
${ }^{5}$ Government defense counsels are typically not selected as arbitrators, and government investment treaty negotiators do not act as arbitrators. In comparison to the WTO Dispute Settlement Mechanism arbitrators in ISDS are typically highly paid star lawyers from prestigious international law firms, while in the WTO many government bureaucrats get appointed without extra pay (Pauwelyn, 2015).

${ }^{6}$ The model allows for an alternative interpretation, along the lines of the Vattenfall case referred to in the introduction. The firm's strategy to file a lawsuit in national court in addition to an international tribunal means that it is less likely that a firm is not compensated. So even if the national and international had the same probability of correctly identifying the state of nature, a multinational firm would have two chances to win a case in the presence of an ISDS based international panel in addition to a national court.

${ }^{7}$ See for example, Art. 4(2) of the German model bilateral investment treaty: "Such compensation must be equivalent to the value of the expropriated investment immediately before the date on which the actual or threatened expropriation, nationalization or other measure became publicly known."
} 
through the national court may take longer if for example the national court could involve a lengthy appeals process and thus in present value terms is less valuable to a firm.

Finally, as a third possible difference I consider how changes in the ambiguity of the law may impact the outcome, that is, the degree to which the firm is entitled to compensation. A higher level of $q$ means that from an ex ante perspective it is more likely that the firm should be compensated in case of regulation, and thus the carve out becomes smaller.

In the following I examine how marginal changes in one of the three parameters $\theta$, $\beta$ and $q$ affect host country and world welfare. Later I also consider possible Pareto improvements by varying two parameters simultaneously. Host country expected welfare at stage 0 equals $\int_{0}^{F^{*}} U^{e} g(F) d F=N^{*} U^{e}$, where $N^{*}$ is the number of firms entering the host country. More specifically, conditional on a firm that enters I obtain for host country welfare in case of

- High court quality:

$$
U^{e}=b-q \cdot\left\{\begin{array}{ccc}
z & \text { if } & z<\beta\left(\pi_{0}-\pi_{1}\right) \\
\beta\left(\pi_{0}-\pi_{1}\right) & \text { if } & z \geq \beta\left(\pi_{0}-\pi_{1}\right)
\end{array}\right.
$$

- Intermediate court quality: For low litigation cost,

$$
U^{e}=b-\left\{\begin{array}{clc}
z & \text { if } & z<(1-\theta) A \\
{[q z+(1-q)(1-\theta) A]} & \text { if } & z \in[(1-\theta) A, \theta A] \\
{[q \theta+(1-q)(1-\theta)] A} & \text { if } & z \geq \theta A,
\end{array}\right.
$$

and for high litigation cost

$$
U^{e}=b
$$

- Low court quality:

$$
U^{e}=b-(1-q) \cdot\left\{\begin{array}{ccc}
z & \text { if } & z<\beta\left(\pi_{0}-\pi_{1}\right) \\
\beta\left(\pi_{0}-\pi_{1}\right) & \text { if } & z \geq \beta\left(\pi_{0}-\pi_{1}\right)
\end{array}\right.
$$

Note that host country welfare depends on court cost $c$ only in case of intermediate court quality, directly in the second and third line of (24) through the term $A$, and indirectly through the demarcation lines for the three sub-regimes.

Expected world welfare at stage $0, \int_{0}^{F^{*}} W^{e} g(F) d F$, can be derived from adding ex- 
pected firm profit (see (18) to (21)) and host country welfare, as shown in (23) to (26). Expected world welfare based on the activity of a single firm depends on the quality of the court as follows

- High court quality:

$$
W^{e}=\pi^{e}+U^{e}=b-F+\pi_{1}+q \cdot\left\{\begin{array}{ccc}
\left(\pi_{0}-\pi_{1}-z\right) & \text { if } & z<\beta\left(\pi_{0}-\pi_{1}\right) \\
0 & \text { if } & z \geq \beta\left(\pi_{0}-\pi_{1}\right)
\end{array}\right.
$$

- Intermediate court quality: In case of low litigation cost

$$
W^{e}=b-F+\left\{\begin{array}{ccc}
\pi_{0}-z & \text { if } & z<(1-\theta) A \\
\pi_{1}+q\left(\pi_{0}-\pi_{1}-z\right)-(1-q) c & \text { if } & z \in[(1-\theta) A, \theta A] \\
\pi_{1}-c & \text { if } & z \geq \theta A
\end{array}\right.
$$

and in case of high litigation cost

$$
W^{e}=b-F+\pi_{1} .
$$

- Low court quality:

$$
W^{e}=\pi^{e}+U^{e}=b-F+\pi_{1}+(1-q) \cdot\left\{\begin{array}{ccc}
\left(\pi_{0}-\pi_{1}-z\right) & \text { if } & z<\beta\left(\pi_{0}-\pi_{1}\right) \\
0 & \text { if } & z \geq \beta\left(\pi_{0}-\pi_{1}\right)
\end{array}\right.
$$

Note that world welfare depends on fixed cost $F$ directly, whereas host country welfare does not. Compensation payments do not appear in world welfare as they are pure transfers between host country and firm. Litigation cost $c$ matter only when court quality is intermediate, as shown in (28), and affect world welfare negatively for high enough externality. In case of low court quality, the firm files frivolous lawsuits and the government prefers to pay compensation if it regulates. Therefore court cost do no matter.

\subsection{Welfare effects of single parameter changes}

\subsubsection{Different court efficiency $\theta$}

When the quality of the court is high a further increase in $\theta$ is neutral for the firm (see (18)), the host country (23), as well as for world welfare (27). Therefore different court 
quality does not change the incentive for a firm to enter the country, and is thus also neutral from an ex ante standpoint. The result suggests that in case of highly developed countries with good own courts there is no benefit from an international court that might further improve the efficiency of the legal system. Intuitively, the firm files a lawsuit if and only if it is rightful and hence there is no room for further improvement. The same logic applies when court quality is low because the firm files only frivolous lawsuits, which leads to either regulation with compensation or no regulation. In both cases, court quality does not matter.

However, when the court quality is intermediate and litigation costs are low, a marginal increase in $\theta$ may improve ex post host country welfare. Note first that an increase in $\theta$ impacts the expected profit of the firm investing in the host country (differentiating (20)) as follows

$$
\frac{d \pi^{e}}{d \theta}=\left\{\begin{array}{ccc}
0 & \text { if } & z<(1-\theta) A \\
-(1-q) A<0 & \text { if } & z \in[(1-\theta) A, \theta A] \\
(2 q-1) A & \text { if } & z \geq \theta A
\end{array}\right.
$$

There is no effect if the externality is small, a negative effect if $z$ is intermediate, and an ambiguous effect for high externalities (depending on the level of $q$ ). To understand this result, it is helpful to recall that the parameters describe an environment in which frivolous and rightful lawsuits occur (see Table 1). The host country government either does not regulate or regulates without compensation, see Figure 1. When the externality is low and the government does not regulate the firm, profits do not depend on court quality (see also (20) and the following analysis). For higher externality values, an increase in $\theta$ may switch policy, but it does so in different directions in the two states of nature depending on the size of $z / A$. This explains why the probability $q$ that determines the occurrence of state of nature appears in (31). Not surprisingly, the change in host country welfare for given firm entry mirrors this pattern (with opposite signs), $\frac{d U^{e}}{d \theta}=-\frac{d \pi^{e}}{d \theta}$.

Turning to the overall effect on host country welfare when $\theta$ changes is less clear when firm entry is taken into account because the welfare effect of firm entry and the change in welfare per firm may move in opposite direction. For example, when the externality is intermediate and litigation cost are low, host country welfare improves from higher court quality per existing firm, but at the same time fewer firms enter. The opposite occurs when the externality is high.

Finally note that the effect of $\theta$ on world welfare is driven only by the firm entry deci- 
sion, as $W^{e}$ itself is independent of $\theta$. If the marginal firm makes a positive contribution to world welfare, an increase in entry has a positive welfare effect.

\subsubsection{Changes in the strength of investor protection $q$}

When the court quality is high, an increase in $q$ leads to lower host country welfare ex post: the derivative of $(23)$ is negative for all $z$. At the same time world welfare is weakly improving in $q$, and strictly so when the externality is small (see 27). Together these observations imply that the firm must be better off when $q$ rises, and that the host country finds an increase in $q$ better only if the higher induced firm profit increases FDI substantially because the direct effect on host country welfare is negative.

A positive welfare effect for the host country can be realized even for given FDI, however, if the country enters a reciprocal agreement with another, symmetric country. In that case, host country welfare, consisting of the welfare arising from inward FDI and the profit of own firms investing abroad, improves weakly because host country welfare in a symmetric case with FDI in both directions is equivalent to world welfare in the previous case of one-way FDI. That is, changes in (27) then measure changes in host country welfare.

Consider next the case of medium court quality. When litigation costs are high, the degree of carve out does not matter for host country and world welfare, as the government regulates without ever being challenged in court. When litigation costs are low however, for given firm entry a negative effect for the host country occurs when the externality is sufficiently high, otherwise the effect is neutral:

$$
\frac{d U^{e}}{d q}=\left\{\begin{array}{ccc}
0 & \text { if } & z<(1-\theta) A \\
-(z-(1-\theta) A) \leq 0 & \text { if } & z \in[(1-\theta) A, \theta A] . \\
-(2 \theta-1) A<0 & \text { if } & z \geq \theta A
\end{array}\right.
$$

The probability $q$ drives the occurrence of being in state $s=0$ or $s=1$. A rise in $q$ makes the latter more likely, and thus the likelihood of compensation payments, which in expected terms harms the government that announces a regulatory policy without compensation and is challenged subsequently in court. At the same time expected firm profits rise and thus make firm entry more attractive, from which the host government benefits. Similar to the case of high court quality, a strong firm response to $q$ is necessary to improve host country welfare when the likelihood of firm compensation rises. World welfare (for given firm entry) is unaffected by $q$ when the externality is either low or high, 
but positive if $z$ is intermediate $\left(d W / d q=\pi_{0}-\pi_{1}-z+c>0\right.$ because $\left.z<\theta A=\beta\left(\pi_{0}-\pi_{1}\right)\right)$. Thus a reciprocal agreement by symmetric countries can (weakly) improve both countries' welfare even when firm responses are absent.

A rise in $q$ is beneficial for the host country when court quality is low because the firm files lawsuits only in state $s=0$, which becomes less important when $q$ goes up. World welfare tends to decline though..

\subsubsection{Differences in size of compensation $\beta$}

A marginally higher $\beta$ (weakly) improves firm profits ex post whenever the externality is large enough because the government prefers to pay compensation regardless of court quality (unless litigation cost are high). FDI is encouraged by this. When the externality is relatively small, and the government does not regulate, the compensation parameter has no effect (see 18, 20 and 21). The opposite effects holds for the host government. Hence a unilateral shift to a higher compensation $\beta$, for example by signing an international investment treaty, can be welfare improving for the host government only if the FDI response is sufficiently strong. As $\beta$ relates to transfer payments between firm and host government, and thus cancel out from a global welfare perspective, world welfare is not directly affected by $\beta$ for given firm entry. Compared to $q$ and $\theta$, changes in $\beta$ have a more limited effect, as it operates only indirectly.

We summarize the findings for all parameters in the following result:

Proposition 7 (effect of ISDS): An ISDS court may differ from a national court in three dimensions: court quality $\theta$, compensation probability $q$, and size of compensation $\beta$.

a) A marginal improvement in court quality $\theta$ has no effect if court quality is high, low, or of medium quality under high litigation cost. When court quality is intermediate and litigation cost are low, however, the effect of higher court quality depends on the externality $z$. The host government benefits from higher court quality when the externality is intermediate, but may be harmed if $z$ is large and $q<0.5$. Regardless of court quality, world welfare is not directly affected by a marginal improvement, only through the change in the number of firms that enter the host country.

b) A marginal increase in the probability of being entitled to compensation $q$ has a (weakly) negative effect on host government welfare for a given firm entry decision regardless of court quality. The host country benefits from ISDS if the induced firm entry is sufficiently strong or for given firm entry a reciprocal agreement between symmetric 
countries is agreed upon.

c) An increase in the size of compensation benefits the host country if the induced firm response outweighs the negative direct effect from higher compensation payments. In a reciprocal agreement between symmetric countries the host countries (weakly) benefit from higher compensation payments.

Proposition 7 may shed some light on recent aspects of investor protection in trade agreements such as CETA and TTP. First, if court quality is sufficiently high, further improvement in court quality do not bring any benefits to host countries. Of course, the threshold for high quality courts in the model cannot easily be measured in practice. Yet, it seems plausible to assume that an international tribunal is not of (much) higher quality than national courts in established democracies with divided powers between the executive and the judiciary. The logic is different if court quality is lower, which presumably is the case in some developing countries. In this case, delegation of arbitration to an international tribunal that has marginally higher quality has the potential to improve host country welfare only under some circumstances because frivolous lawsuits may plague the system.

Strengthening investor protection through international laws tends to harm host countries as compensation payments become more likely. A positive host country welfare effect requires that stronger investor protection induces substantial more FDI or own firms investing abroad benefit from a reciprocal deal. The latter may be less relevant for relatively poor developing countries, so that the key for higher investor protection to work must come from an elastic response of firms entering the host country when profits expectations increase.

Finally, more beneficial compensation terms in case of regulation benefit the firm and thus tend to induce more FDI. The size of compensation may be higher under international law either because international law typically calls for full compensation or because an international tribunal is less costly than pushing a claim through a national legal system with potentially subsequent challenges in higher courts. This could be an argument for industrialized countries to agree bilaterally to an ISDS based system, as it more effectively guarantees compensation in case of regulation.

\subsection{Pareto improvements for multiple parameter changes}

Proposition 7 shows that marginal variations of one parameter often lead to opposite welfare effects for the host country and the firm. But different parameter changes lead to 
different winners and losers, which suggests that combined changes of parameters might lead to a Pareto improvement. For example, consider the case of high court quality, under which a marginal change in court quality has no effect on either side. Hence a focus on simultaneous changes in $q$ and $\beta$ seems promising. However, $\beta$ has no welfare effect when the externality is small, $z<\beta\left(\pi_{0}-\pi_{1}\right)$, but a positive one for the firm when the externality is above the threshold. Through sufficiently large changes in the compensation parameter a policy switch between a policy of compensation payment in case of regulation and a policy of no regulation can be induced in state $s=1$.

Proposition 8 (Pareto improving ISDS): a) Assume court quality is high. A Paretoimprovement is possible if and only if $z \in\left[\beta\left(\pi_{0}-\pi_{1}\right),\left(\pi_{0}-\pi_{1}\right)\right]$. The reform requires increasing $\beta$ and lowering $q$.

b) Assume court quality is intermediate. Then no Pareto improvement is possible when initially either litigation cost are low and the externality is small $(z<(1-\theta) A)$, or litigation cost are high.

c) Assume court quality is low. A Pareto-improvement is possible if and only if $z \in$ $\left[\beta\left(\pi_{0}-\pi_{1}\right),\left(\pi_{0}-\pi_{1}\right)\right]$. The reform requires increasing $\beta$ and raising $q$.

Proof: a) When $z<\beta\left(\pi_{0}-\pi_{1}\right)$, a change in $q$ cannot lead to a Pareto improvement because the boundary condition for the externality is unchanged and $q$ has opposite welfare effects on firm and host country. The same applies for an isolated $\beta$ change that leaves the externality below the compensation payment. Therefore, a sufficient fall in the compensation parameter from $\beta$ to $\hat{\beta} \leq z /\left(\pi_{0}-\pi_{1}\right)$ that reverses the boundary condition is the only chance. Without a simultaneous adjustment in $q$, the firm is worse off however, because $(1-q) \pi_{1}+q \pi_{0}>(1-q) \pi_{1}+q \pi_{1}+q \hat{\beta}\left(\pi_{0}-\pi_{1}\right)$. A simultaneous increase in $q$ to $\hat{q}$ can make the firm better off, which is the case when $q<\hat{\beta} \hat{q} q^{*}$ or $q /\left(\hat{\beta} \hat{q} q^{*}\right)<1$. At the same time, the host country is better off iff $b-q z<b-\hat{q} q^{*} \hat{\beta}\left(\pi_{0}-\pi_{1}\right)$, which is equivalent to $\left(\pi_{0}-\pi_{1}\right) / z<q /\left(\hat{q} q^{*} \hat{\beta}\right)$. Together the conditions for a Pareto improvement therefore require that $z>\pi_{0}-\pi_{1}$, but this is in conflict with the assumption that we were initially in a situation with a low externality.

Consider now the situation in which initially $z>\beta\left(\pi_{0}-\pi_{1}\right)$. Again, a change in $\beta$ alone cannot make the host country better off. A change in $q$ alone does not make both sides better off. Consider a simultaneous increase in the compensation parameter from $\beta$ to $\hat{\beta}>z /\left(\pi_{0}-\pi_{1}\right)$, which switches the policy from regulation with compensation to no regulation in state 1 . The firm is better off if $1>q \beta / \hat{q}$, while the host country is better off when $q \beta / \hat{q}>z /\left(\pi_{0}-\pi_{1}\right)$. Therefore a necessary condition for a Pareto improvement is that $z<\pi_{0}-\pi_{1}$, which is violated if the externality is too high, but is feasible if 
$z \in\left[\beta\left(\pi_{0}-\pi_{1}\right),\left(\pi_{0}-\pi_{1}\right)\right]$.

Notice that $q$ must fall in the reform. The condition for host country welfare improvement requires $q \beta / \hat{q}>z /\left(\pi_{0}-\pi_{1}\right)$ and $z>\beta\left(\pi_{0}-\pi_{1}\right)$. The two conditions cannot hold simultaneously if $\hat{q} \geq q$.

b) When litigation cost are high, there is no room for Pareto improvement because the government always regulates without threat of a lawsuit and cannot be made better off. When litigation cost are low and the externality is sufficiently low, the government does not regulate. Hence the firm cannot be made better off.

c) The proof follows the proof in case of high court quality. When $z<\beta\left(\pi_{0}-\pi_{1}\right)$, decreasing the compensation parameter from $\beta$ to $\hat{\beta} \leq z /\left(\pi_{0}-\pi_{1}\right)$ makes the firm better off if $1<\hat{\beta}(1-\hat{q}) /(1-q)$, while an increase in host country welfare necessitates $z /\left(\pi_{0}-\pi_{1}\right)>$ $(1-\hat{q}) \hat{\beta} /(1-q)$. Together the conditions contradict the assumption of a low enough externality. The opposite logic applies when we start from a high externality situation and increase $\beta$. Firm profit increases if $(1-q) \beta /(1-\hat{q})<1$, while host welfare goes up when $(1-q) \beta /(1-\hat{q})>z /\left(\pi_{0}-\pi_{1}\right)$. The two conditions are compatible only if the externality lies between the compensation payment and the first best policy switching point. The condition for host country welfare improvement then implies that $q$ must rise in the reform.q.e.d

Proposition 8 shows that combined parameter changes can improve welfare of both sides under certain conditions. In case of low and high court quality, a Pareto improvement is possible if initially the regulatory policy is inefficient in the absence of courts, namely the government regulates but it should not from a world welfare perspective. The reform is not trivial, however, as it requires an induced policy switch, here from regulation with compensation to no regulation. In case of intermediate court quality, things are straightforward in two situations either because under high litigation cost there is no threat of lawsuit and thus no constraint on the government, or under low litigation cost and small externality the government doesn't regulate. Things are more complicated in the latter situation when the externality is larger, as then regulation and court challenges do occur. Because lawsuits are wasteful, it is likely that a Pareto improving reform can be found similar to the one under high court quality if the government can be induced to not regulate with appropriate compensation in terms of compensation probability. 


\section{Conclusion}

In this paper I have proposed a framework to study the role of investor protection laws and institutions when foreign direct investment faces a hold up problem due to ex post regulation. A novel perspective is provided through the possible mistakes made by a court, that is awarding compensation for regulation when none should be given, and not ruling in favor of compensation when it should. This aspect influences both the decision of firms whether to litigate against compensation without regulation and for governments to pursue such a policy in the first place. The framework allows me to address policy issues such regulatory chill and the possible benefits from delegating decision power to an international tribunal away from national courts. Key parameters are the quality of the court in the sense of the probability of taking a wrong decision, the strength of investor protection in the law, and the size of compensation in case the government pays one.

The paper sheds light on the debate on regulatory chill. While it is true that from a global welfare perspective there is no underregulation, the model suggests that from a host country perspective regulatory chill may occur in some circumstances, which involve frivolous lawsuits, where due to bad court quality the host government abstains from regulation even in a situation where the firm should not be compensated. Identifying the circumstances of such a case to occur in practice is difficult, but the result shows where to look for. Interestingly, it is not the case where the externality from no regulation is very large, but rather intermediate because otherwise the host country would have regulated with compensation.

The paper carries several policy implications. First, inefficiently low entry induced by the hold up problem can be mitigated by strengthening investor protection (the probability of having the right to compensation), as alternative to FDI subsidies. Moreover, shifting power to a ISDS tribunal may sometimes lead to a Pareto improvement. The following factors appear to support this: i) firms respond elastically to improvements of their expected profits when ISDS law is more generous to firms, as this brings more benefits to the country from FDI; ii) similar countries simultaneously shift power to ISDS, if firm profits are valued as much as other benefits and cost from FDI because then host countries gain from the benefits their own firms enjoy in their outward investment, and

finally iii) changing several parameters at the same time; for example, even when court quality is high, increasing the compensation rate but lowering the probability of compensation can be beneficial for host country and foreign investor if initially the externality would have led to excessive regulation in the absence of courts. It is interesting to ask 
whether the latter type of changes could also be done at the national level, i.e., changes in domestic laws governing investor protection, the quality of courts, and compensation payments to firms in case of regulation. The quality of courts is perhaps the one component that can be changed the least easily nationally, and therefore delegating the power to an international body is simpler. By shifting to ISDS common standards relating to the degree of compensation and carve outs come typically with it, which would be perhaps harder to implement nationally.

I have made some restrictive assumptions that should be relaxed in future work. For example, many aspects of the court system are independent of the size of the externality, such as the likelihood of the court correctly identifying the state of nature, the cost of going to court, etc. While it is conceivable that the qualitative nature of the relationships are captured reasonably well in the present model, determining in practice the precise change in parameters to improve outcomes may depend well on a better modeling of these aspects in which the relationship is more complex.

From a normative perspective, further instruments might bring advantages. For instance, the compensation payment paid by the government could exceed the award obtained by the firm (known as decoupling). The difference represents a fine and could go to

a third party. In the law and economics literature this has been shown to be the case, see Polinsky and Che (1991), and more recently Choi and Sanchirico (2004) and Garoupa and Sanchirico (2010). Decoupling tends to make compensation payments for governments less attractive, and by itself does not help to solve the underinvestment problem due to the hold-up problem. However, in case of frivolous regulation - governments exploit the weakness of the court system by regulating the without paying compensation voluntarily - a fine would discipline government actions. The litigation cost are another parameter of the model that influences the equilibrium outcome. The level of these cost could be influenced by policy. Evaluating changes in $c$ is likely to be non-trivial because it influences the level of court cost relative to the compensation payment as well as the policy and litigation choices for given litigation cost regimes (high or low). Exploring this avenue is left for future research.

\section{References}

Aisbett, E., Karp, L. and C. McAusland (2010a): Police Powers, Regulatory Takings and the Efficient Compensation of Domestic and Foreign Investors, Economic Record 86, September, 367-383.

Aisbett, E., Karp, L. and C. McAusland (2010b): Compensation for Indirect Expro- 
priation in International Investment Agreements: Implications of National Treatment and Rights to Invest, Journal of Globalization and Development 1, Article 6

Alschner, W. (2013): Interpreting investment treaties as incomplete contracts: Lessons from contract theory, mimeo.

Bagwell, K. and R.W. Staiger (2001a): Domestic Policies, National Sovereignty, and International Economic Institutions, Quarterly Journal of Economics 116(2), 519-562.

Bagwell, K. and R.W. Staiger (2001b): The WTO as a mechanism for Securing Market Access Property Rights: Implications for Global Labor and Environmental Issues, Journal of Economic Perspectives 15 (3), 69-88.

Berger, A., Busse, M., Nunnenkamp, P., Roy, M. (2011). More Stringent BITs, Less Ambiguous Effects on FDI? Not a Bit!. Economics Letters, 112 (3), 270-272.

Berger, A., Busse, M., Nunnenkamp, P., Roy, M. (2013). Do Trade and Investment Agreements Lead to More FDI? Accounting for Key Provisions Inside the Black Box. International Economics and Economic Policy, 10 (2), 247-275.

Blonigen, B.A. and J. Piger (2011): Determinants of Foreign Direct Investment, NBER Working Paper 16704.

Bronckers, M. (2015): Is Investor-State Dispute Settlement (ISDS) Superior to Litigation before domestic courts? An EU View on Bilateral Trade Agreements, Journal of International Economic Law 18(3), 655-677.

Busse, M., Königer, J. and P. Nunnenkamp (2010): FDI Promotion through bilateral investment treaties: more than a bit? Review of World Economics 146(1), 147-177.

Choi, A. and C.W. Sanchirico (2004): Should Plaintiffs Win What Defendants Lose? Litigation Stakes, Litigation Effort, and the Benefits of Decoupling, The Journal of Legal Studies Vol. 33, No. 2, 323-354

Dietz, T. and M. Dotzauer (2015): Political Dimensions of Investment Arbitration: ISDS and the TTIP negotiations, Zentra Working Papers in Transnational Studies No. 48.

European Commission (2013): Investment Protection and Investor-to-State Dispute Settlements in EU agreements, November.

Gaukrodger, D. and K. Gordon (2012): Investor-state dispute settlement: A scoping paper for the investment policy community, OECD Working Papers on International Investment, Nor. 2012/3.

Garoupa, N. and C.W. Sanchirico (2010): Decoupling as Transactions Tax, The Journal of Legal Studies Vol. 39, No. 2, 469-496.

Gerstetter, C. and N. Meyer-Ohlendorf (2013): Investor-state dispute settlement un- 
der TTIP - a risk for environmental regulation? Ecological Institute, Berlin.

Horn, H. and T. Tangeras (2017): Economics and Politics of International Investment Agreements, CEPR Discussion Paper No. DP11879.

Kleinheisterkamp, J. (2014): Is there a need for investor-state arbitration in the Transatlantic Trade and Investment Partnership (TTIP), LSE Law Department.

Kohler, W. and F. Stähler (2016): The Economics of Investor State Protection: ISDS versus National Treatment, CESifo Working Paper No. 5766.

Konrad, K. (2017): Large investors, regulatory taking and investor-state dispute settlement, European Economic Review 98, 341-353.

Landeo, C.M., Nikitin, M., and S. Baker (2006): Deterrence, Lawsuits, and Litigation Outcomes under Court errors, Journal of Law, Economics, and Organization 23, 57-97.

Lando, H. and M.C. Mungan (2018): The effect of type-1 error on deterrence, International Review of Law and Economics 53, 1-8.

Neumayer, E., Nunnenkamp, P., Roy, M. (2016). Are Stricter Investment Rules Contagious? Host Country Competition for Foreign Direct Investment through International Agreements. Review of World Economics, 152 (1), 177-213.

Nikiema, S.H. (2012): Best Practices Indirect Expropriation, International Institute for Sustainable Development; March 2012.

Pauwelyn, J. (2015): WTO Panelists are from Mars, ICSID Arbitrators are from Venus, Why? And does it matter? mimeo.

Polinsky, A.M. and Y.-K. Che (1991): Decoupling Liability: Optimal Incentives for Care and Litigation, RAND Journal of Economics 22, 562-70

Stähler, F. (2017): An optimal investor state dispute settlement mechanism, mimeo.

Tienhaara, K 2011, 'Regulatory Chill and the Threat of Arbitration: A View from Political Science', in Chester Brown and Kate Miles (ed.), Evolution in Investment Treaty Law and Arbitration, Cambridge University Press, Cambridge UK, pp. 606-627.

UNCTAD (2015): Recent Trends in IIAS and ISDS, IIA Issues Note No. 1, February. UNCTAD (2018): Investor-State dispute Settlement: Review of Developments in 2017, IIA Issues Note No. 2, June.

Willington, M. (2013): Hold Up Under Costly Litigation and Imperfect Courts of Law, Journal of Law, Economics, \& Organization, 29, 1023- 1055. 
Table 1: Firm litigation decision in case of regulation without compensation

\begin{tabular}{|c|c|c|c|}
\hline & $\begin{array}{l}\text { Low court quality } \\
\theta \theta \min \left\{\theta^{*}, 1-\theta^{*}\right\}\end{array}$ & $\begin{array}{l}\text { Medium court quality } \\
\begin{array}{c}\boldsymbol{\theta} \in\left[\min \left\{\boldsymbol{\theta}^{*}, 1-\boldsymbol{\theta}^{*}\right\}\right. \\
\left.\max \left\{\boldsymbol{\theta}^{*}, 1-\boldsymbol{\theta}^{*}\right\}\right]\end{array}\end{array}$ & $\begin{array}{l}\text { High court quality } \\
\theta>\max \left\{\theta^{*}, 1-\theta^{*}\right\}\end{array}$ \\
\hline $\begin{array}{l}\text { Low litigation cost } \\
\theta^{*}<0.5\end{array}$ & Only frivolous lawsuits & $\begin{array}{l}\text { Rightful and frivolous } \\
\text { lawsuits }\end{array}$ & Only rightful lawsuits \\
\hline $\begin{array}{l}\text { High litigation cost } \\
\theta^{*}>0.5\end{array}$ & Only frivolous lawsuits & No lawsuits & Only rightful lawsuits \\
\hline
\end{tabular}




\section{Figure 1: Policy choice and court quality}

$$
\text { State } s=0
$$

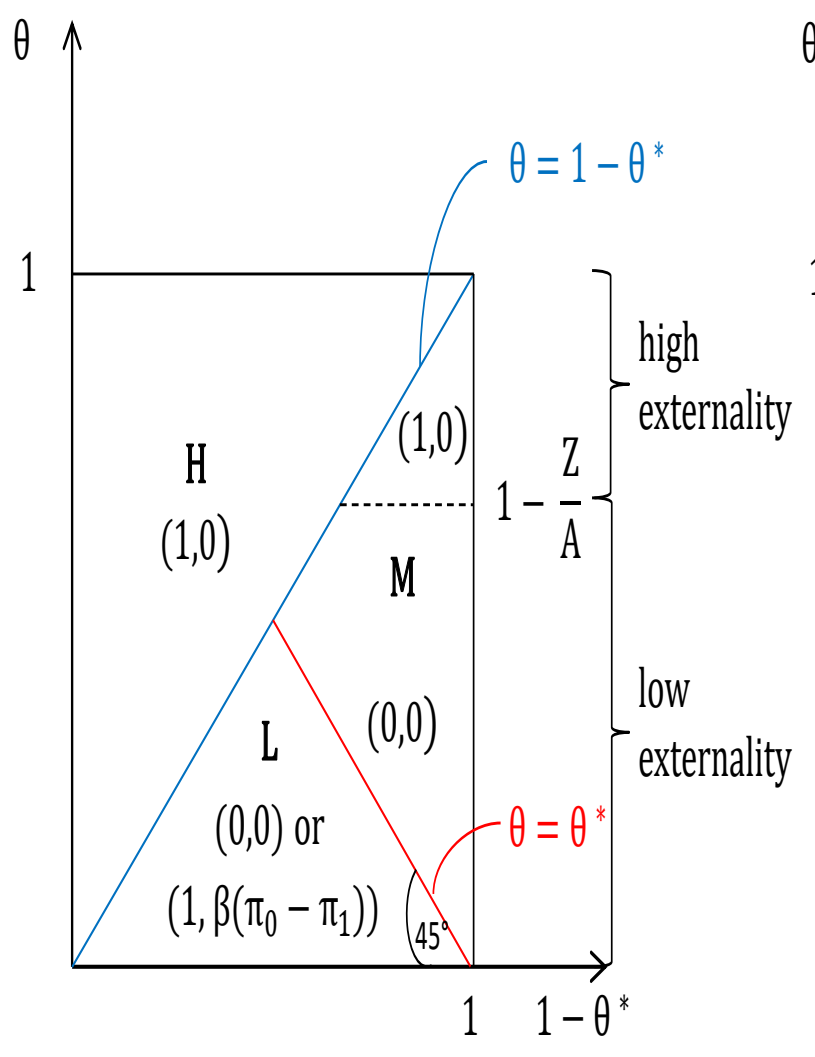

State $s=1$

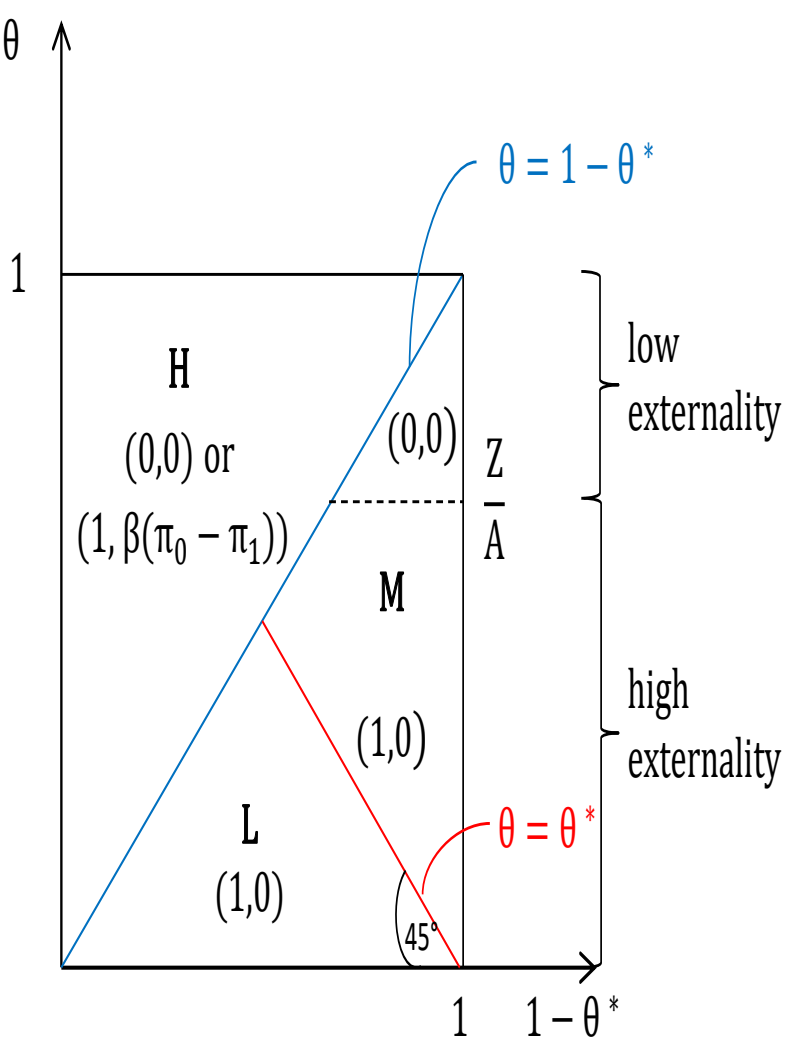

L, M, H stand for low, medium, and high court quality

The graphs show the situation for low litigation cost; in case of high litigation cost, the x-axis measures $\theta^{*}$ (instead of $1-\theta^{*}$ ) $;$ the policy choice is as in the above graph, except for the case of medium court quality where it always is $(1,0)$ both under $s=0$ and $s=1$ 